\title{
Cuando la revelación no es transparencia Posibilidades de un diálogo filosófico - teológico desde la propuesta de Byung-Chul Han
}

\author{
When the revelation is not transparency \\ Possibilities of a philosophical-theological dialogue from the proposal of \\ Byung-Chul Han
}

\author{
Juan Pablo Espinosa Arce \\ Magister en Teología \\ Pontificia Universidad Católica de Chile \\ jpespinosa@uc.cl \\ Fecha de recepción: 26/03/2019
}

Fecha de aceptación: 23/04/2019

Como citar este artículo: J.P. ESPINOZA “Cuando la revelación no es transparencia. Posibilidades de un diálogo filosófico - teológico desde la propuesta de Byung-Chul Han” en Palabra y Razón. Revista de Teología, Filosofía y Ciencias de la Religión Nº15, Julio 2019, pp. 43-59 https://doi.org/10.29035/pyr.15.61

Resumen: El presente artículo, proveniente de la disciplina teológica, busca pensar un diálogo filosófico-teológico en torno al concepto de "revelación", central en el cristianismo, a partir de algunas intuiciones presentes en la filosofía del pensador surcoreano Byung-Chul Han. La tesis que se propone es sostener que la revelación no constituye una transparencia, y que cuando Dios se revela al ser humano - y también cuando un ser humano se hace manifiesto a otro dicha comparecencia no constituye una manifestación total. En la revelación persiste un halo de misterio, de ignorancia o de negatividad. Considerar la posibilidad de un diálogo entre Filosofía y Teología representa, a nuestro entender, un acercamiento necesario a la búsqueda de la verdad en el ambiente académico y en la práctica de una renovada docencia universitaria.

Palabras clave: Revelación, negatividad, eros, misterio, Byung-Chul Han

Abstract: The present article, coming from the theological discipline, seeks to think a philosophicaltheological dialogue around the concept of "revelation", central in Christianity, from some intuitions present in the philosophy of the South Korean thinker Byung-Chul Han. The thesis What is proposed is to maintain that revelation does not constitute a transparency, and that when God reveals himself to the human being - and also when a human being becomes manifest to another - this appearance does not constitute a total manifestation. In the revelation there persists a halo of mystery, ignorance or negativity. Considering the possibility of a dialogue between Philosophy and Theology represents, in our opinion, a necessary approach to the search for truth in the academic environment and in the practice of a renewed university teaching.

Key words: Revelation, negativity, eros, mystery, Byung-Chul Han 


\section{Estado de la cuestión}

La figura filosófica del pensador surcoreano Byung-Chul Han se ha transformado en un referente novedoso y provocador para acercarse al tratamiento de los temas filosóficos. Podemos reconocer en Han un pensador de la creación de categorías por medio de las cuales se comprenden las coordenadas socioculturales actuales. ${ }^{1}$ Temas como "la sociedad del cansancio", "topología de la violencia", "sociedad de la transparencia", "agonía del eros", son conceptos que, recuperando la tradición de pensadores como M. Heidegger, W. Benjamin, H. Jonas o J. Baudrillard, ofrecen al lector una forma amistosa y cotidiana de hacer filosofía. Byung-Chul Han realizó estudios en Filosofía, Literatura y Teología, elementos que, sumados a una notable sensibilidad por lo estético, lo corporal y lo cultural, busca tender puentes entre distintas disciplinas epistemológicas. En vistas a este camino iniciado por el mismo autor, nuestra propuesta busca realizar un diálogo filosófico-teológico al concepto de "revelación" el cual es fundamento de la fe cristiana.

A nivel de la teología fundamental, la revelación se puede entender como "la palabra que Dios dirige a la humanidad"2. Latourelle la denomina como "la primera realidad cristiana, el primer hecho, el primer misterio, la primera categoría. Toda la economía de la salvación, en el orden del conocimiento, descansa en este misterio de la automanifestación de Dios"'. En el darse a conocer de Dios, que alcanza su punto culminante con la manifestación histórica de Jesucristo (Cf. Jn 1,14; Gal 4,4; Heb 1,1-2), los seres humanos pudieron hacer experiencia sensible-estética de Aquél que era el ícono del Dios invisible (Cf. Col 1,15). Ahora bien, la revelación no constituye una sobre-exposición del que se da a conocer. No se puede entender la revelación como un conocimiento completo, perfecto o definitivo. En la automanifestación de Dios se mantiene un velo que sigue ocultando al manifestado. El mismo Latourelle en otro momento señala que "el Dios de la nueva alianza, como el de la antigua, permanece oculto.

La revelación es un conocimiento indirecto, imperfecto, parcial y oscuro. Algo separa siempre el enunciado y la realidad, el testimonio y la presencia, la revelación revelada y la revelación revelante" ${ }^{\text {. En }}$ este no saber o en la ignorancia que se

\footnotetext{
${ }^{1}$ Para un conocimiento "de síntesis" de su obra se puede revisar: M, REYES PUIG, "Filosofando con Byung-Chul Han", en https://blogs.herdereditorial.com/filco/filosofando-con-byung-chul-han/ [Recuperado el 11/01/2019].

${ }^{2}$ R. LATOURELLE. Teología de la revelación. Sígueme: Salamanca 1979, p. 9.

${ }^{3}$ R. LATOURELLE. Teología de la revelación, p. 9.

${ }^{4}$ R. LATOURELLE. Teología de la revelación, p. 525.
} 
genera en la revelación, se impide que el revelado sea reducido a un objeto dentro de una lista de otros objetos. El teólogo alemán Karl Rahner, a propósito de este dejo de misterio-halo de lo oculto, reconoce: "el Inefable, el Innominable, el que no puede ser encasillado en el mundo como uno de sus elementos; el Silencioso, siempre presente y siempre pasado por alto y desoído; aquél, que en el fondo, ninguna palabra puede expresar debidamente, pues toda palabra sólo recibe limitación, sonido propio, y de esta manera una significación comprensible, dentro de un campo lingüístico"s.

Hay en la revelación un carácter apofático, negativo, limitado. Gracias a esa limitación el sujeto creyente continúa su búsqueda de Aquél que le fue comunicado. Es interesante comprobar que gracias al elemento de lo oculto, de lo no mostrado totalmente, acontece la experiencia mística, la espiritualidad, la misma fe. Gracias a ese no saber se recrea continuamente la búsqueda del fundamento de sentido de la vida del creyente cristiano. Este no saber, o ignorancia, la reconocemos en la base de las intuiciones de Byung-Chul Han. En la lectura atenta de sus obras, podemos reconocer retazos teológicos, explícitos e implícitos, los cuales nos proveen de categorías para pensar la fe, lo religioso y la misma teología. Para evidenciar las posibilidades de este diálogo filosófico-teológico hemos optado por el concepto de revelación que hemos presentado sucintamente al comienzo de este artículo. La tesis que queremos proponer es que la revelación no significa transparencia. Cuando a nivel antropológico un ser humano entra en comunicación con otro ser humano, dicha proximidad no queda totalmente desvelada y es gracias a ese velo que cubre la realidad del otro que se generan los vínculos de interés, búsqueda y relación afectiva. Y, en el caso de Dios del que ya hemos reseñado algunas claves, su manifestación histórica tampoco cae en la transparencia total. Dios permanece oculto, en una proximidad lejana, en una lejanía cercana.

Para efectos metodológicos, nuestro artículo seguirá el siguiente itinerario: la presentación del concepto de transparencia y de sociedad de la transparencia en Byung-Chul Han para, desde él, comprender qué significa el permanecer oculto del Dios revelado. De esta muestra de contrarios avanzaremos hacia la positiva negatividad del misterio, de lo oculto y del silencio místico (como distancia). Para Han el cambio epistemológico y experiencial que debe provocarse en medio de la sociedad de la transparencia es recuperar la dimensión de lo oculto, tanto a nivel antropológico como en el nivel teológico que nosotros estamos proponiendo, lo cual se condensa en el concepto del eros. Finalmente, reseñar algunas claves para pensar el diálogo filosófico-teológico que estamos presentando. Dicho diálogo constituiría

\footnotetext{
${ }^{5}$ K. RAHNER. La gracia como libertad. Herder: Barcelona 2008, p. 18.
} 
una experiencia de sabiduría, de actitud de búsqueda, de toma de distancia frente al objeto-sujeto conocido y una apertura a otras formas de entendimiento de la realidad. Pensar filosófica y teológicamente la realidad exigen una actitud de silencioso respeto ante las grandes preguntas de la existencia humana, las cuales no son totalmente respondidas por las disciplinas que hemos puesto en diálogo. Una filosofía y una teología de carácter propositiva constituye, a nuestro entender, un desafío en la academia y en la docencia universitaria.

\section{La Sociedad de la transparencia y la la muerte del misterio}

Ofrezcamos en primer lugar la tesis que Byung-Chul Han presenta en su obra La sociedad de la transparencia ${ }^{6}$ que es de la cual tomamos la noción de que la revelación no es sinónimo de transparencia. Dice Han: "ningún otro lema domina hoy tanto el discurso público como la transparencia. Esta se reclama de manera efusiva, sobre todo en relación con la libertad de información"’. Es un fenómeno interesante comprobar cómo las instituciones, y a causa de las crisis de legitimidad, representación y liderazgo, han resuelto asumir la transparencia y la probidad como elementos centrales de su acción en el espacio público ${ }^{8}$. Ahora bien, si seguimos de cerca la línea argumentativa de Han, nos daremos cuenta que su comprensión de la transparencia supera el reduccionismo al que se puede ver confinado este término si solo lo pensamos en términos de evitar prácticas corruptivas. En la transparencia, tal y como es entendida por el pensador asiático hay una profunda marca antropológica que es la que buscamos recuperar para efectos de este artículo. Es más, Han dice que esta "omnipresente exigencia de transparencia [...] no puede reducirse al ámbito de la política y de la economía".

Entonces, si la transparencia supera el reduccionismo político y económico, ¿cómo se entiende desde su antropo-lógica? Para responder esta cuestión es necesario comprender cuáles son las categorías que están emparentadas con la sociedad de la transparencia. Han dice que esta cultura de lo transparente es una sociedad

\footnotetext{
${ }^{6}$ La edición original en alemán es de 2012 y la versión castellana editada en Herder es de 2013. Seguiremos la edición en español: B.-C. Han. La sociedad de la transparencia. Herder: Barcelona 2013.

${ }^{7}$ B.-C. Han. La sociedad de la transparencia, p. 11.

${ }^{8}$ Un caso concreto: el Gobierno chileno estableció la "Agenda de transparencia y probidad" como elementos centrales de las funciones políticas y sociales de la administración. Dicha Agenda es definida como: "La Agenda de Probidad y Transparencia es un conjunto de propuestas que refleja el compromiso del Gobierno para mejorar de manera sustancial la calidad de la política y el ejercicio de la actividad pública", Gobierno de Chile, Agenda de Probidad y Transparencia en http://www.lasnuevasreglas.gob. cl/ [Recuperado el 11/01/2019].

${ }^{9}$ B.-C. Han. La sociedad de la transparencia, p. 11
} 
positiva. En su filosofía, el concepto de lo positivo tiene características negativas. Lo positivo sería: mantener prácticas de marginación, de expulsión de la diferencia, de ocultamiento de la fragilidad y de la vulnerabilidad, de un excesivo culto a la acumulación y al rendimiento. La sociedad de la transparencia está íntimamente hermanada con la sociedad del cansancio ${ }^{10}$, ambas son espacios en donde prima un "infierno de lo igual" 1 . En este infierno de lo igual sólo hay un conjunto de egos inconexos entre sí, incapaces de generar una comunidad ${ }^{12}$, tema que abordaremos en la segunda parte de este artículo.

El infierno de lo igual, como síntoma antropológico, se entiende en ByungChul Han desde dos términos contrapuestos: lo pornográfico y el eros. La primera categoría es comprendida por Han en los siguientes términos: "es el contacto inmediato entre la imagen y el ojo"13. La experiencia de lo pornográfico acontece con un golpe inmediato de la vista con el objeto, y que cuando ocurre la inmediatez de la visión surge, a juicio de Han, la lógica del precio, de la compra y de la venta. El objeto visto por el ojo pornográfico sólo es entendido como mercancía, como una cosa sujeta a las leyes de la transacción. Incluso esto afecta a la persona humana: cuando se mira al otro desde una lógica de lo pornográfico estamos reduciendo a dicha persona a un mero objeto.

Estas intuiciones son ofrecidas también en otra obra de Han, a saber, La agonía del eros. En ella el filósofo surcoreano dice que "las imágenes porno muestran la mera vida expuesta" ${ }^{\prime 4}$. En la vida expuesta no existe la complejidad de las relaciones interpersonales porque sólo se relaciona con objetos. No hay problematización,

\footnotetext{
${ }^{10}$ En la obra de Han La sociedad del cansancio se presenta la tesis de que hoy la persona si trabaja más, si vive sujeta al rendimiento competitivo es más feliz. La felicidad se evalúa en términos de narcicismo. Es más, Han llegará a sostener que la violencia que se ejerce sobre el sujeto ya no es externa, sino que es interna, neurológica. Esto se puede entender desde el siguiente planteamiento del autor presente en su obra La expulsión de lo distinto: percepción y comunicación en la cultura actual. Herder: Barcelona, 2017: "Los tiempos en los que existía el otro se han ido. El otro como misterio, el otro como seducción, el otro como eros, el otro como deseo, el otro como infierno, el otro como dolor va desapareciendo. Hoy, la negatividad del otro deja paso a la positividad de lo igual" (B.-C. Han. La expulsión de lo distinto, p. 9).

${ }^{11}$ B.-C. Han. La sociedad de la transparencia, p. 12.

${ }^{12}$ El pensador japonés, filósofo y educador budista Daisaku Ikeda reconoce esta desconexión antropológica como signo de la cultura actual que surge con la modernidad. Dice Ikeda: "quiero recordar que cuando los seres humanos cortan sus vínculos con la naturaleza y el universo, también dejan marchitar y morir los lazos recíprocos que los unen con sus semejantes. La consecuencia es que el hombre termina aislándose en su soledad; y lo peor de todo es que, a fuerza de parecer "normal", la situación deja de ser vista como un problema" (D. IKEDA. El nuevo humanismo. FCE: México 2013, p. 20.

${ }^{13}$ B.-C. Han. La sociedad de la transparencia, p. 12.

${ }^{14}$ B.-C. Han. La agonía del eros. Herder: Barcelona 2014.
} 
no hay filosofía ni poesía, porque el lenguaje poético, filosófico o religioso pertenecen a la esfera de lo mistérico, de lo oculto, de lo que no es transparente. Y lo contrario a esto religioso, a lo sagrado del misterio es la profanación. Han dice que "la transformación del mundo en porno se realiza como su profanación"15. En la profanación usufructuamos el lugar reservado a lo divino. Si lo sagrado son las cosas separadas, lo pornográfico como infierno de lo igual que profana elimina esa distancia e iguala todo. La sociedad de lo igual es simétrica, en cambio lo sagrado, el culto, el misterio es asimétrico ${ }^{16}$. En la sociedad de la transparencia accedemos a la muerte del misterio. Y, con la muerte del misterio, terminamos transformando al ser humano en un objeto funcional al sistema. En palabras de Han "la coacción de la transparencia nivela al hombre mismo hasta convertirlo en un elemento funcional de un sistema. Ahí está la violencia de la transparencia" ${ }^{17}$.

\section{El Eros: salida crítica a la sociedad de la transparencia}

Ahora bien, lo opuesto a lo pornográfico es el eros. El eros es entendido por Han desde diferentes modalidades o categorías, entre las que se destaca la presencia del otro en cuanto otro, en cuanto sujeto interpelante que invita al interpelado a deconstruir su propia experiencia personal, social, espiritual. El eros es entendido por Han como un corte a la sociedad de lo igual. Dice este autor: "el Eros se dirige al otro en sentido enfático, que no puede alcanzarse bajo el régimen del yo. Por eso, en el infierno de lo igual, al que la sociedad actual se asemeja cada vez más, no hay ninguna experiencia erótica. Esta presupone la asimetría y la exterioridad del otro" 18 . Esta exterioridad y relación tiene una clave constitutiva que la sociedad del rendimiento trata de eliminar, a saber, la vulnerabilidad connatural del ser humano. La vulnerabilidad, lo frágil, la enfermedad, la diferencia, la pobreza ${ }^{19}$, la muerte, son contrarias a la sociedad de lo pulido ${ }^{20}$.

\footnotetext{
${ }^{15}$ B.-C. Han. La agonía del eros, p. 48.

${ }^{16}$ Se sugiere revisar la obra de X. PIKAZA, Experiencia religiosa y cristianismo: introducción al misterio de Dios. Sígueme: Salamanca, 1981). Pikaza define lo sagrado como "trascendencia, más allá de todo ser-saber-obrar del hombre" (X. PIKAZA, Experiencia religiosa, p. 236. Lo sagrado no "permite" una reducción a conceptos estáticos, por ello se habla de lo sagrado-separado desde distintas metáforas, símbolos o narrativas. Por ello lo sagrado es profundamente asimétrico, porque supone un evitar objetivar la misma trascendencia.

${ }^{17}$ B.-C. Han. La sociedad de la transparencia, p. 14.

${ }^{18}$ B.-C. Han. La agonía del eros, p. 10.

${ }^{19}$ Se recomienda la lectura atenta de la obra de A. CORTINA. Aporofobia, el rechazo al pobre. Un desafio para la democracia. Paidós: Chile, 2018). Lo opuesto a la exclusión del pobre, y del pobre migrante, es en Cortina la "razón cordial", la cual se estructura desde la igual dignidad y la compasión. ${ }^{20}$ Esta es otra categoría propuesta por Byung-Chul Han: "Lo pulido, pulcro, liso e impecable es la señal de identidad de la época actual. ¿Por qué lo pulido nos resulta hoy hermoso? Más allá de su efecto estético, refleja un imperativo social general: encarna la actual sociedad positiva. Lo pulido e
} 
Pero acontece un problema antropológico con un exceso de positividad o de lo pulido, a saber, la falta de experiencias fundantes en la vida humana. La experiencia surge desde la negatividad, de un dolor, de una experiencia pre-epistémica. Dice Han: "lo que constituye la experiencia en un sentido enfático es la negatividad de lo distinto y de la transformación. Tener una experiencia con algo significa que eso nos concierne, nos arrastra, nos oprime o nos anima. Su esencia es el dolor. Pero lo igual no duele. Hoy, el dolor cede paso a ese "me gusta" que prosigue con lo igual" Detengámonos aquí, ya que estas indicaciones comenzarán a perfilar la comprensión de que la revelación no es sinónimo de la transparencia.

Lo primero que Han indica es que la negatividad de lo distinto tiene un poder performativo. La herida, el misterio, lo escondido, el eros, tiene una capacidad de problematizar la cuestión humana. Comienzan a surgir una serie de preguntas que exigen ampliar el horizonte de comprensión humana y entender que el verdadero aprendizaje supone poner en cuestión los conocimientos aparentemente finalizados. Un auténtico aprendizaje performativo o transformador tiene la capacidad de concernirnos (involucrarnos, gustarnos, implicarnos, atrevernos a ellos), nos arrastra (y también podemos arrastrar a otros, en cuanto carácter comunitario del aprendizaje del mundo, del ser humano y de lo trascendente) y también nos puede oprimir en cuanto experiencia de dolor, conmoción o protesta frente a la injusticia. Ese es el poder movilizador y problematizador del eros. En cambio, la imagen paradigmática del "me gusta" muy ligado a las redes sociales ${ }^{22}$ no genera problematización. Por ello Han lo relaciona con lo "igual". Lo igual es una respuesta simplista ante la problemática humana, en cambio la conmoción exige una respuesta creativa y

impecable no daña. Tampoco ofrece ninguna resistencia. Toda negatividad resulta eliminada" (B.-C. Han. La salvación de lo bello. Herder: Barcelona, 2015, p. 11. Lo sugestivo de la negatividad que resulta eliminada es que ella, a juicio de Han, tiene un valor salvífico. De modo implícito recuerda el pasaje de Isaías 53 en el Antiguo Testamento cuando el autor sagrado presenta la imagen del "siervo doliente de Yahvé" quien logra la salvación del pueblo gracias a sus heridas, a su sangre injustamente derramada y a su muerte. También es la imagen aplicada al mismo Jesucristo en su pasión y muerte. En el dolor, por lo tanto, hay una belleza, una paradójica belleza que es necesario saber descubrir y educar. En palabras de Han esto es presentado de la siguiente manera: "el mundo de lo pulido es un mundo de hedonismo, un mundo de pura positividad en el que no hay ningún dolor, ninguna herida, ninguna culpa [...] pero ella (la sociedad de lo pulido) no da a luz a ningún redentor, a ningún homo doloris cubierto de heridas y con una corona de espinas" (B.-C. Han. La salvación de lo bello. Herder: Barcelona, 2015, p.16. En clave pedagógica considero necesario que la filosofía y la teología, así como las demás ciencias humanas y sociales continúen y refuercen sus enseñanzas en torno al reconocimiento del dolor y de la vulnerabilidad del ser humano. Es necesario aprender a trabajar con estos elementos propios del ser humano que la sociedad del rendimiento y, en particular, sus formas educativas han omitido en gran medida. Una teología, una filosofía atenta al sufrimiento, a la fragilidad, constituye un elemento que puede surgir en futuras investigaciones y publicaciones.

${ }^{21}$ B.-C. Han. La expulsión de lo distinto, p. 12.

${ }^{22}$ El like que muestra el pulgar levantado en signo de aprobación. 
comunitaria ante el mismo problema. Por ello el eros tiene el carácter de ser una crítica social, política, religiosa o cultural ante la legitimación de lo igual que afecta directamente al ser humano. La conmoción, el dolor, la herida es movilizadora de una práctica que debe tener la justicia como elemento central.

En la conmoción reconocemos el concepto de las lagunas presente en la propuesta filosófica de Han. La laguna la entenderemos como un no saber, como una sana ignorancia, con la instauración del misterio que ha sido destruido por la sociedad de la transparencia. Han reconoce que "la sociedad de la transparencia no permite lagunas de información ni de visión" ${ }^{23}$. El saber y el ver como elementos de un conocimiento que se va revelando. Aquí comienza a perfilarse el tema concreto de la revelación que no se somete al imperativo de la transparencia. Los sentidos están puestos al servicio del conocimiento, y el conocimiento precisa de un vacío. En el vacío-laguna Han intuye que la lógica del cálculo no tiene un espacio válido, porque el cálculo en su propuesta marca siempre el mismo resultado. No hay apertura a otra posibilidad de resolución. En cambio la laguna-vacío involucra la creación de otro pensamiento, que puede moverse entre la intuición, la inspiración, lo poético, la filosofía o la estética. Lo interesante es que se marca una diferencia epistemológica entre un modo de entender unívoco y un tránsito equívoco. En palabras de este filósofo "la transparencia o la univocidad serían el final del Eros, es decir, la pornografía"24.

El lenguaje equívoco es el lenguaje del misterio, porque no es sobreexposición transparente sino que abre el espacio a la imaginación, a la fantasía, al juego y a la recreación de experiencias y comprensiones de la realidad. Además el lenguaje equívoco así como el misterio tienen la peculiaridad de ser lentos y progresivos. Es el enfrentamiento del tiempo acelerado y del tiempo de la lentitud ${ }^{25}$, o entre un tiempo sin aroma y un tiempo con aroma ${ }^{26}$ respectivamente. En el tiempo sin aroma no hay un espacio o una distancia entre el observante y lo observado (lógica de

\footnotetext{
${ }^{23}$ B.-C. Han. La sociedad de la transparencia, p. 17.

${ }^{24}$ B.-C. Han. La sociedad de la transparencia, p. 36.

${ }^{25}$ Zygmunt Bauman hace también la distinción entre el tiempo de la velocidad y la lentitud. A partir de un análisis del impacto de la televisión en el ser humano, Bauman - haciéndose eco de las intuiciones de P. Bourdieu - dice que en el tiempo de velocidad ya no queda tiempo para "reflexionar y sopesar los argumento $[\ldots]$ no hay tiempo para hacer una pausa y pensar dos veces antes de emitir un juicio, se le otorga un privilegio inadvertido a las ideas recibidas, ideas triviales, compartidas por todos, que no exigen ni necesitan reflexión porque se consideran obvias y que, como los axiomas, no necesitan ser sometidas a prueba" (Z. BAUMAN. La sociedad sitiada. FCE: Argentina 2013, pp. 199-200).

${ }^{26}$ Hacemos referencia a conceptos presentes en la obra de B. B.-C. Han. El aroma del tiempo. Un ensayo filosófico sobre el arte de demorarse. Herder: Barcelona, 2015. Anteriormente habíamos ofrecido algunas pistas sobre esta obra en el artículo JP. ESPINOSA ARCE, "Un tiempo con aroma", en Posiciones: revista de debate estratégico en https://www.revistaposiciones.cl/2018/12/20/untiempo-con-aroma/ [Recuperado el 12/01/2019].
} 
lo pornográfico), en cambio en el tiempo que posee aroma hay una experiencia de la distancia que, como dice Heidegger - citado en Han - es una "cercanía que reserva" 27 . En la distancia entendemos la lentitud. Es más, "la existencia propia es lenta" ${ }^{28}$. Necesitamos tiempo para aprender a ser seres humanos, para alcanzar las metas que nos proponemos, para aprender conocimientos nuevos. Hay una tensión temporal entre la búsqueda y el hallazgo, tensión que involucra la problematización de las cuestiones en las que nos sumergimos. Pareciera ser que esto es la clave de una sana epísteme: una constante actitud de apertura, de pregunta y de asombro ante lo que desconocemos y un esfuerzo maduro por acercarse a ello que anhelamos conocer. El deseo epistemológico tiene entrada en la lógica del misterio, del eros (incluso de un eros pedagógico), de lo que está en la distancia (literalmente lo sagrado). La lentitud desbarata la competitividad porque la segunda busca lo inmediato para posicionarse en el terreno privado-público. En cambio, la lentitud, consciente de su fragilidad y de su no saber, debe esforzarse un poco más para acceder a esto nuevo del conocimiento.

Es necesario, por tanto, que una auténtica pedagogía del misterio ${ }^{29}$, por ejemplo, sea capaz de educar en los estudiantes ese deseo de abrirse a otras formas de conocimiento, siempre en diálogo con otros de manera de ampliar, progresivamente, los conocimientos previos. Por ello la lentitud del misterio posee una dimensión espiritual, de apertura a otros, al mundo y a la trascendencia. Por ello Han-haciéndose eco de las palabras de Hegel - sostiene: "este demorarse es la fuerza mágica que lo trueca en el ser. En cambio, carece de espíritu quien se limita a zapear a través de lo positivo. El espíritu es lento porque se demora en lo negativo y lo trabaja para sí” ${ }^{\prime 3}$.

\footnotetext{
${ }^{27}$ B.-C. Han. El aroma del tiempo, p. 93.

${ }^{28}$ B.-C. Han. El aroma del tiempo, p. 95.

${ }^{29}$ El psiquiatra chileno y académico de la PUC, Sergio Canals Lambarri, considera que en una auténtica pedagogía debe existir un reconocimiento al valor de la espiritualidad y al misterio. Dice Canals: "más que nunca es necesario inculcar desde pequeño al niño el valor de la espiritualidad humana. Más aún que avizore permanentemente que detrás de un mundo frío, racional y tecnologizado existe algo que está más allá y que es difícil de descubrir si no existe una auténtica actitud de búsqueda frente a esta otra realidad. Es indispensable reconocer la existencia de una oscuridad luminosa, es decir, una oscuridad donde uno intuye la presencia de algo que está más allá, algo que descubrir, contra la oscuridad opaca de un mundo sin espesor" (S. CANALS. El poder de la caricia. Lo que debemos saber y manejar para proteger a los adolescentes de las drogas y otras conductas equivocadas. Grijalbo: Santiago de Chile, 2001, p. 154. Junto con ello es necesario advertir que en la reflexión de Han, misterio tiene que ver con la negatividad, con lo no pulido, con aquello que va saliendo del margen de la normalidad y lo establecido. Aquí negatividad representa un concepto no peyorativo, sino que es el inicio para profundizar de nueva manera el conocimiento de las cosas, que como hemos propuesto en este caso involucra el conocimiento de Dios.

${ }^{30}$ B.-C. Han. La sociedad de la transparencia, p.18.
} 


\section{Cuando la revelación no es transparencia : posibilidades del diálogo filosófico- teológico}

La negatividad es una experiencia perforadora, que trueca lo positivo desenmascarando su función legitimadora de violencia antropológica. En la positividad hay "un vacío de sentido" 31 por la falta de distancia contemplativa. Por ello Han sostiene que "en virtud de la falta de distancia, no es posible ninguna contemplación estética ninguna demora [...] la cercanía es rica en espacio, mientras que la falta de distancia lo aniquila. La cercanía lleva inscrita una lejanía. Por eso está lejos" ${ }^{32}$. Es interesante esto de la cercanía rica en espacio, porque muestra el sustento del concepto de revelación, concepto sobre el cual hemos querido trazar las posibilidades de un diálogo filosófico-teológico.

El Misterio de lo revelado se sustenta en lo que Han denomina la "tensión erótica" ${ }^{33}$, la cual está fundada a su vez en una dialéctica del oculto-manifiesto, de lo revelado-velado, de la "aparición-desaparición" ${ }^{34}$. La revelación precisa de un velo que mantenga lo desconocido de aquél que se ha mostrado exteriormente. En la confesión de fe cristiana, Dios se mueve en esta riqueza que el espacio genera gracias a la tensión erótica del manifiesto-oculto. La experiencia cristiana indica que Dios es una realidad persona que está radicalmente cercana al ser humano, sobre todo por la Encarnación en la cual los seres humanos vimos la gloria de Dios en Jesucristo (Cf. Jn 1,14). Pero esta cercanía se mantiene en lo lejano, lo escondido y lo silencioso, en lo que impide ser mercantilizado o cosificado. Este es el carácter apofático y sagrado de la experiencia de Dios, en cuanto nuestros conceptos no pueden capturar totalmente su presencia. La dialéctica del oculto-manifiesto es, quizás, el mejor modo de entender la revelación del Dios de la Biblia, y a la vez, la mejor manera de entender nuestra propia condición antropológica de mostrarse-mostrarnos pero también ocultarnos, dejando un espacio íntimo de silencio y de misterio. La vida de Dios y con Dios y la vida con el otro se mueven en el terreno del enigma. El filósofo Miguel García-Baró reconoce la importancia fundamental del enigma en la comprensión de la realidad misma. Dice García-Baró:

"la experiencia del enigma es realmente la matriz de toda otra experiencia, porque la vida que queda en el paso de ella es un territorio al que no es posible regresar con ningún método ni con ninguna violencia. Toda la estructura de la existencia queda

\footnotetext{
${ }^{31}$ B.-C. Han. La sociedad de la transparencia, p. 32.

${ }^{32}$ B.-C. Han. La sociedad de la transparencia, p. 33.

${ }^{33}$ B.-C. Han. La sociedad de la transparencia, p. 51.

${ }^{34}$ B.-C. Han. La sociedad de la transparencia, p. 52.
} 
marcada por la inicial experiencia del enigma, por el choque inicial y brutal, sin preparativos, como un trauma, con la seriedad de la vida en marcha continua hacia la muerte" 35 .

Ahora bien, ¿por qué es necesario que el ser humano y nuestra comprensiónacogida del Dios revelado se mantengan en esta lógica del enigma? ¿qué aporta la intimidad del misterio y del no saber a nuestra propia experiencia de mundo o de la trascendencia? ¿Cómo hablar del Dios Misterio y del ser humano misterio en la sociedad de la transparencia? Dice Han: "sin duda el alma humana necesita esferas en las que pueda estar en sí misma sin la mirada del otro. Lleva inherente una impermeabilidad" 36 . En el alma humana el elemento de la conciencia, de la intimidad, de lo más sagrado-separado reconocemos esta esfera que busca no ser aprisionada por una violencia transparente ${ }^{37}$. En la persona de Dios acontece un movimiento similar: Él se nos da en un movimiento de extremo amor pero que no puede ser reducido a una transparencia funcional.

Cuando el ser humano y Dios se van mostrando - y también encontrando en la dinámica de la fe - se expresa lo que Han llama el despertar de la ternura en la relación. Dice el filósofo surcoreano: "a la imposición de la transparencia le falta precisamente esta ternura que no es sino el respeto a una alteridad que no puede eliminarse por completo" 38 . La actitud de la distancia que mira con respeto (literalmente: que es capaz de mirar de nuevo; re-spectare) la alteridad radical del otro es capaz de no oprimir dicha otredad y que la deja ser por sí misma. Sería interesante proponer una filosofía y una teología de la ternura que, conscientes de la presencia del otro, sean capaces de reeducar el misterio de la trascendencia y de la projimidad.

En el acercamiento a la revelación que no es transparencia, Han recuerda que "lo santo no es transparente. Más bien, traza una borrosidad misteriosa. El reino venidero de la paz no se llamará sociedad de la transparencia. Esta no es ningún estado de paz" ${ }^{39}$. Ante lo santo-misterioso-separado, el ser humano mantiene una actitud de búsqueda, de pregunta y de asombro. Esa es la capacidad de lo Otro-

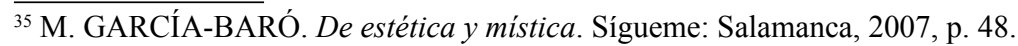

${ }^{36}$ B.-C. Han. La sociedad de la transparencia, p. 14.

${ }^{37}$ Juan de Sahagún Lucas, a propósito de este no "encasillar" dice: "el carácter misterioso de lo sagrado radica en su superioridad ontológica. Porque se sitúa en un nivel distinto, resulta imposible encasillarlo en el marco de nuestras categorías y expresarlos en términos tomados del lenguaje ordinario" (J. SAHAGÚN LUCAS. Fenomenología y Filosofia de la Religión. BAC: Madrid, 1999, p. 103.

${ }^{38}$ B.-C. Han. La sociedad de la transparencia, p. 16.

${ }^{39}$ B.-C. Han. La sociedad de la transparencia, p. 38.
} 
Trascendente: ser un elemento que provoca seducción al que lo contempla. Por ello Han califica el Misterio como "sinuoso" ${ }^{40}$, quebradizo, desigual, opuesto totalmente a lo pulido, elemento que ya hemos revisado anteriormente. Lo sinuoso representa un esfuerzo físico y anímico para llegar al lugar proyectado. En lo sinuoso entra el seductor como paradigma de aquél que se muestra eróticamente (como deseo) para parecer atrayente al buscador.

Si uno recorre, por ejemplo, las páginas de los textos sapienciales y proféticos de la Biblia hebrea - lo que es nuestro Antiguo Testamento - se puede dar cuenta cómo Dios actúa como un amante que busca cortejar y seducir a su amada (que es la imagen de Israel) para conformar con ella una alianza salvadora ${ }^{41}$. Esta alianza tiene el carácter del enigma, en cuanto no se deja mostrar completamente. Avanza lentamente, de manera de seducir al espíritu humano: "la seduciré, la llevaré al desierto y le hablaré al corazón" (Oseas 2,14). Las metáforas y lenguajes poéticos de carácter equívoco, como las usadas por la literatura profética y sapiencial de la Biblia ${ }^{42}$ y que son distintos al cálculo de lo único de la transparencia, son las herramientas que el seductor utiliza para despertar el deseo de acercarse al Misterio. La fantasía y el encanto son propios de la sociedad del misterio. Por ello, Han recupera la experiencia teológica y filosófica de San Agustín al querer acercarse a Dios. Dice Han: "según Agustín, Dios utiliza metáforas y oscureció la Sagrada Escritura intencionadamente, para engendrar más placer: De ahí que las cosas estén cubiertas con una especie de envoltura figurativa, para que mantengan activo el entendimiento del hombre que investiga con actitud piadosa, y no parezcan carentes de valor al ofrecerse sin velos (nuda) y abiertamente (promta)"43.

Lo oscuro de las metáforas tiene la facultad de generar el anhelo, la búsqueda, un sentido de deseo y de gusto ante lo que/el que se va mostrando. Lo oculto genera mayor deseo-ardor. Dios utiliza lo metafórico, lo apofático para manifestarse de

\footnotetext{
${ }^{40}$ B.-C. Han. La sociedad de la transparencia, p. 31.

${ }^{41}$ Uno de los profetas que más representa esta relación esponsal de Dios con el pueblo es Oseas. Oseas es "el profeta del amor, ve su matrimonio como una parábola de la relación Dios-Israel. Dios es el marido; Israel, la esposa. Esta ha sido infiel; lo ha abandonado para irse con otro (Baal - dioses extranjeros) o con otros (Asiria y Egipto). Dios nos ama como un esposo a una esposa: la ley del Sinaí es como un contrato amoroso, como una alianza entre esposos" (EQUIPO BÍBLICO CLARETIANO. Suscité profetas entre sus hijos: Libros proféticos. Editorial Claretiana: Buenos Aires, 2000, p. 44.

${ }^{42}$ El Cantar de los Cantares es el modelo prototípico para entender las metáforas de seducción para comprender al otro y también a Dios. En este libro "la calidad del lenguaje, sus artificios poéticos, su inmensa riqueza de signos, metáforas y símbolos, sus alusiones a la historia de su pueblo" muestran la sutileza para insinuar y atraer al lector (EQUIPO BÍBLICO CLARETIANO. Derramará como lluvia su sabiduría. Editorial Claretiana: Buenos Aires, 2001, p. 239.

${ }^{43}$ B.-C. Han. La sociedad de la transparencia, p. 42.
} 
mejor manera y poder así provocar un deseo en el ser humano al querer conocerlo. Por ello, dice Han que "la capa erotiza la palabra, elevándola a la condición de un objeto de deseo. La palabra actúa con mayor poder de seducción cuando está revestida figurativamente. La negatividad de la reconditez transforma la hermenéutica en una erótica. Descubrir y descifrar se realizan como un desvelamiento agradable"44. Por ello la revelación no es transparencia, por ello la transparencia es opuesta al misterio, por ello el misterio supone una distancia erótica, una tensión epistémica, un vacío agradable que busca, ardorosamente, ser completado en una intelección madura, abierta y dialogante al modo de la interdisciplina.

Entre la filosofía y la teología existen elementos comunes que pueden dialogar en vistas a pensar y recrear una pedagogía del misterio, una actitud de pregunta asombrada, de búsquedas permanentes que proponga reflexiones de sentido para el ser humano de la época. En medio de los desafíos académicos y de docencia universitaria, entender cómo el diálogo interdisciplinar entre filosofía y teología representa un espacio de aprendizaje clave al momento de buscar responder las grandes preguntas de la existencia. Lograr una filosofía o una teología que, atenta a su tradición pueda ir explicitando de manera creativa sus conceptos fundacionales significa pensar dichas epistemes desde una lógica propositiva. En este artículo hemos optado por pensar el concepto de revelación, elemento basal del cristianismo a la luz de la filosofía del pensador surcoreano Byung-Chul Han desde la tesis de que revelación no es transparencia, sino que involucra la conciencia del misterio, tanto a nivel antropológico como teológico. Asumir la experiencia de la fe, la creencia, la búsqueda de la sabiduría filosófica, el dejarnos encontrar por la verdad, son elementos que deben continuarse pensando desde estos fecundos encuentros entre ciencias afines. Sólo así la Academia podrá vislumbrar, de manera siempre progresiva, en camino, qué significa el aporte del diálogo fe y razón como instancia de transformación personal y comunitaria.

\footnotetext{
${ }^{44}$ B.-C. Han. La sociedad de la transparencia, p. 43.
} 